\title{
International Space Station Air Quality Assessed According to Toxicologically-Grouped Compounds
}

\author{
John T. James ${ }^{1}$ and Thomas F. Limero ${ }^{2}$ \\ Johnson Space Center, Houston, Texas, 77058, USA \\ Steve Beck ${ }^{3}$ \\ Johnson Space Center, Houston, Texas, 77058, USA \\ Patti F. Cheng ${ }^{4}$ \\ Johnson Space Center, Houston, Texas, 77058, USA \\ Vanessa J. de Vera ${ }^{5}$ \\ Johnson Space Center, Houston, Texas, 77058, USA \\ Jennifer Hand ${ }^{6}$ \\ Johnson Space Center, Houston, Texas, 77058, USA \\ and \\ Ariel Macatangay ${ }^{7}$ \\ Johnson Space Center, Houston, Texas, 77058, USA
}

\begin{abstract}
Scores of compounds are found in the International Space Station (ISS) atmospheric samples that are returned to the Johnson Space Center Toxicology Laboratory for analysis. Spacecraft Maximum Allowable Concentrations (SMACs) are set with the view that each compound is present as if there were no other compounds present. In order to apply SMACs to the interpretation of the analytical data, the toxicologist must employ some method of combining the potential effects of the aggregate of compounds found in the atmospheric samples. The simplest approach is to assume that each quantifiable compound has the potential for some effect in proportion to the applicable SMAC, and then add all the proportions. This simple paradigm disregards the fact that most compounds have potential to adversely affect only a few physiological systems, and their effects would be independent rather than additive. An improved approach to dealing with exposure to mixtures is to add the proportions only for compounds that adversely affect the same physiological system. For example, toxicants that cause respiratory irritation are separated from those that cause neurotoxicity or cardio-toxicity. Herein we analyze ISS air quality data according to toxicological groups with a view that this could be used for understanding any crew symptoms occurring at the time of the sample acquisition. In addition, this approach could be useful in post-flight longitudinal surveys where the flight surgeon may need to identify post-flight, follow-up medical studies because of on-orbit exposures that target specific physiological systems.
\end{abstract}

\footnotetext{
${ }^{1}$ Chief Toxicologist, Habitability \& Environmental Factors Div., 2101 Nasa Pkwy, Houston/SF23, non-member

${ }^{2}$ Laboratory Supervisor, Toxicology Section, 2101 Nasa Pkwy, Houston/SF23/Wyle, non-member

${ }^{3}$ Senior Scientist, Toxicology Section, 2101 Nasa Pkwy, Houston/SF23/Wyle, non-member

${ }^{4}$ Scientist, Toxicology Section, 2101 Nasa Pkwy, Houston/SF23/Wyle, non-member

${ }^{5}$ Scientist, Toxicology Section, 2101 Nasa Pkwy, Houston/SF23/Wyle, non-member

${ }^{6}$ Scientist, Toxicology Section, 2101 Nasa Pkwy, Houston/SF23/Wyle, non-member

${ }^{7}$ Senior Scientist, Environmental Control \& Life Support, 2101 Nasa Pkwy, Houston/SF23/Wyle, non-member
} 


\section{Introduction}

$\mathrm{O}$ NE critical problem with long-duration missions to distant celestial bodies is the lack of immediate communication with earth-based controllers. During current missions the crews of spacecraft are usually in a location that enables them to contact ground-based controllers to help diagnose and respond to any problem. One of the most important conditions associated with crew health during spaceflight is air quality. Harmful air quality can have an immediate and disabling effect on the crew. For distant missions the crew must be able to use complex analytical data to diagnose and respond to air quality problems, hopefully before an acute problem arises. This paper illustrates how complex chemical data can be transformed into a dimension that can be readily understood by the crew.

\section{Raw Analytical Data on Compounds Present in Air}

Historically the atmosphere within a human-rated spacecraft has been assessed by periodic sampling and later ground-based analysis of the samples using sophisticated instruments. The instrumants are far too large and unreliable to be candidates for spaceflight; however, much smaller and more reliable instruments with somewhat diminished capability are being flown on an experimental basis. For 8 months the Air Quality Monitor, based on gas chromatography/differential mobility spectrometry, has been flown as a detailed test objective (DTO) aboard the International Space Station (ISS). ${ }^{1}$ NASA plans to upgrade the current DTO instrument to an instrument capable of quantifying a target list of 20-30 compounds and displaying analytical data to the crew on each compound as frequently as every half hour. Initially data will be displayed in bar-graft format with the length of the bar representative of the concentration of the compound in the air (Fig. 1). This will be visually indexed against the

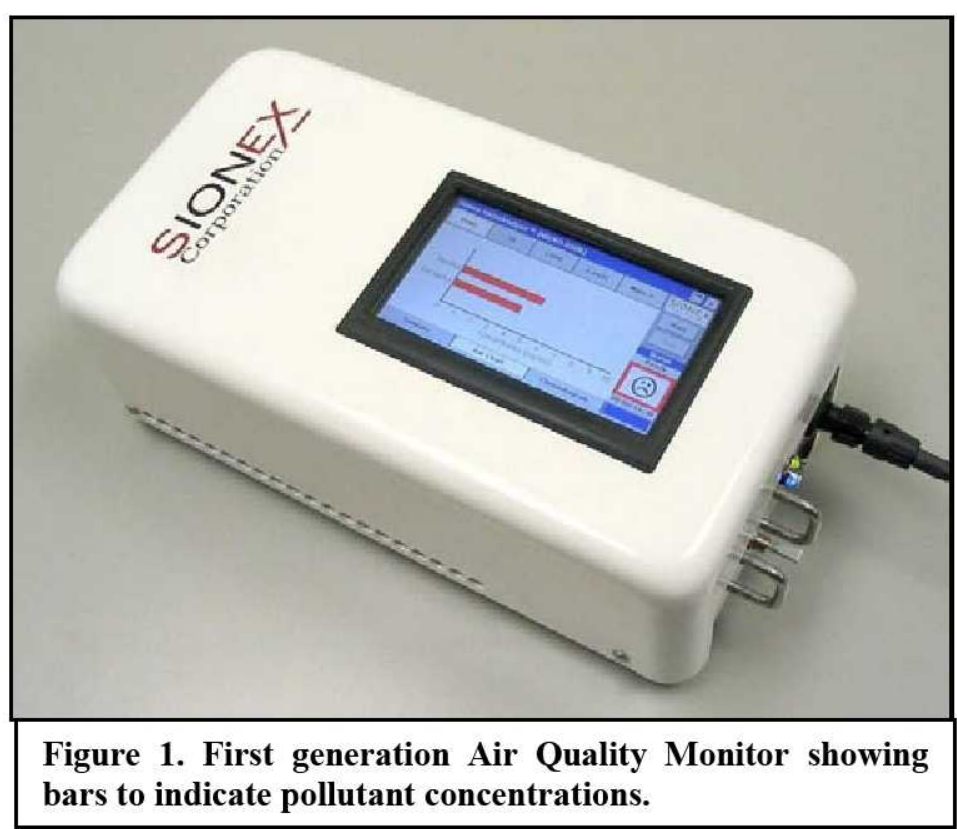
spacecraft maximum allowable concentrations (SMACs) for a predetermined length of exposure to the compound. ${ }^{2}$

Although not fully determined at present, if a measured concentration approachs the SMAC, then the color of the bar will go from green to yellow. If the SMAC is exceeded, then the bar will turn orange. This method of communicating air quality data to the crew appears adequate, but several key shortcomings suggest the need for much more relevant communication. One shortcoming is that the crew has no idea what sort of immediate health effects could develop because a component of air quality has exceeded its SMAC. A second shortcoming is that some health effects could develop later after the mission has ended. Investigators performing longitudinal health assessments on astronauts have no guidance on what adverse effects to target as they follow changes in an astronaut's health status over many years following the mission. A third shortcoming is that exposures are always to more than one compound and such an exposure could involve additive effects of the compounds present. A fourth shortcoming is that exposures over long times can be especially important if cumulative effects can be induced by the airborne toxicants. Our goal is to convert the analytical-chemistry data using SMACs into an information form that assists the crew in understanding how their health could be affected, and to facilitate longitudinal studies of astronaut health after the flight.

To illustrate how analytical data can be converted we will begin with the simulated data set shown in Table 1 . These data are representative of a "worst case" scenario as taken from several actual data sets from the atmosphere of the ISS. 


\begin{tabular}{|c|c|c|c|c|c|c|c|c|}
\hline \multirow{3}{*}{$\begin{array}{l}\text { Compound } \\
\text { Methanol } \\
\end{array}$} & \multirow{3}{*}{$\begin{array}{l}\begin{array}{l}\text { 180-day } \\
\text { SMAC } \\
\left(\mathbf{m g} / \mathbf{m}^{3}\right)\end{array} \\
90\end{array}$} & \multicolumn{6}{|c|}{ Simulated Worst-Case Concentrations over Six Months } & \multirow{3}{*}{$\begin{array}{l}\begin{array}{l}\text { 6-month } \\
\text { average } \\
\left(\mathrm{mg} / \mathrm{m}^{3}\right)\end{array} \\
0.45\end{array}$} \\
\hline & & \multicolumn{2}{|c|}{122} & 3 & 4 & \multicolumn{2}{|c|}{5} & \\
\hline & & 0.5 & 0.32 & 0.4 & 0.5 & 0.5 & 0.45 & \\
\hline Ethanol & 2000 & 5.0 & 7.0 & 3.0 & 4.0 & 6.0 & 5.0 & 5.0 \\
\hline Acetaldehyde & 4 & 1.0 & 1.2 & 0.7 & 1.1 & 1.1 & 1.1 & 1.0 \\
\hline Propenal & 0.02 & 0.01 & 0.03 & 0.03 & 0.01 & 0.01 & 0.03 & 0.02 \\
\hline Acetone & 50 & 1.0 & 1.5 & 0.5 & 0.5 & 0.3 & 0.7 & 0.75 \\
\hline 2-propanol & 150 & 2.0 & 1.0 & 0.0 & 1.0 & 1.0 & 1.0 & 1.0 \\
\hline Pentane & 9 & 0.2 & 0.1 & 0.1 & 0.1 & 0.2 & 0.2 & 0.15 \\
\hline Dichloromethane & 10 & 0.3 & 0.2 & 0.1 & 0.3 & 0.2 & 0.1 & 0.2 \\
\hline Butanal & 13 & 0.2 & 0.2 & 0.1 & 0.3 & 0.2 & 0.2 & 0.2 \\
\hline 1-butanol & 40 & 0.5 & 0.3 & 0.4 & 0.6 & 0.2 & 0.4 & 0.4 \\
\hline 2-methylhexane & 12 & 0.1 & 0.1 & 0.1 & 0.1 & 0.1 & 0.1 & 0.1 \\
\hline 2,3-dimethylpentane & 12 & 0.1 & 0.1 & 0.1 & 0.1 & 0.1 & 0.1 & 0.1 \\
\hline Pentanal & 16 & 0.1 & 0.1 & 0.1 & 0.1 & 0.1 & 0.1 & 0.1 \\
\hline 3-Methylhexane & 12 & 0.1 & 0.1 & 0.1 & 0.1 & 0.1 & 0.1 & 0.1 \\
\hline 1-heptane & 12 & 0.1 & 0.1 & 0.1 & 0.1 & 0.1 & 0.1 & 0.1 \\
\hline Heptanal & 20 & 0.1 & 0.1 & 0.1 & 0.1 & 0.1 & 0.1 & 0.1 \\
\hline Isoprene & 3 & 0.2 & 0.4 & 0.3 & 0.4 & 0.3 & 0.2 & 0.3 \\
\hline Carbon monoxide & 17 & 5.0 & 3.0 & 3.0 & 6.0 & 5.0 & 3.0 & 4.0 \\
\hline Formaldehyde & 0.12 & 0.05 & 0.04 & 0.03 & 0.04 & 0.05 & 0.03 & 0.04 \\
\hline Trimethylsilanol & 4 & 2.0 & 1.5 & 1.2 & 1.8 & 1.0 & 1.5 & 1.5 \\
\hline Carbon dioxide & 13,000 & 6,000 & 8,000 & 5,000 & 4,000 & 6,000 & 7,000 & 6,000 \\
\hline
\end{tabular}

\section{Spacecraft Maximum Allowable Concentrations}

Guidelines have been set by NASA in cooperation with the National Research Council Committee on Toxicology (NRCCOT) for approximately 60 compounds that have been found in spacecraft atmospheres or could enter spacecraft atmospheres as the result of an accidental release. These address potential exposure durations from 1 hour to 1000 days. The short-term limits are for exposures during unexpected releases and permit a slight risk of minor effects such as headache or eye irritation. The long term limits are set for time-weighted-average exposures during a long and distant mission and are set to protect against any adverse effect. Limits have been set for 180-days to be applied to astronauts who live and work aboard ISS for a half year. The 1000-day limits were set for exploration-class missions.

In the early 1990s, as we began to set limits in cooperation with the NRCCOT, the consensus emerged that we had to designate specifically which adverse effects we were protecting against with each SMAC. To our knowledge no other regulatory expert group had ever done this before. By doing this we have made it possible to transform measured concentrations into potential specific effects on a target organ or system, and then combine the potential effects of all other compounds that target the same organ system. For example, halocarbons tend to sensitize the heart to elicit arrhythmias, which can be life threatening. If more than one halocarbon were present in the vehicle atmosphere, then the additive effects of each one must be considered.

The means of combining the effects of a group of compounds that target a specific organ or system is by no means fully developed. Typically, studies show that at lower concentrations, compounds tend to be no worse than additive in effect at the same biological target: ${ }^{3}$ therefore, we will assume that they are additive in proportion to their applicable SMAC. Suppose there are four cardiotoxicants identified in the spacecraft atmosphere at concentrations as follows: F11 $=35 \mathrm{ppm}, \mathrm{F} 113=20 \mathrm{ppm}, \mathrm{F} 12=108 \mathrm{ppm}$, and F21 $=30 \mathrm{ppm}$. The risk of a cardiotoxic effect from these compounds depends on the individual concentration being above a specific threshold concentration; therefore, the SMACs are the same regardless of the time of exposure. If a certain concentration of a given Freon is exceeded even for one hour, then the risk of arrhythmia becomes unacceptable. For the four Freons in our example the SMACs are as follows: F11 $=140 \mathrm{ppm}, \mathrm{F} 113=50 \mathrm{ppm}, \mathrm{F} 12=540 \mathrm{ppm}$, and F21 $=50 \mathrm{ppm}^{4-7}$ Inspection of the hypothetical concentrations shows that none of the concentrations exceeds its respective SMAC. However, we would expect the arrhythmogenic effects of the Freons to be additive in proportion to their respective SMACs. The Eq. that expresses this relationship is as follows: 


$$
{ }_{\mathrm{a}} \mathrm{T}_{\mathrm{e}}={ }_{\mathrm{a}} \sum_{\mathrm{e}}\left(\mathrm{C}_{\mathrm{i}} / \mathrm{e} \mathrm{SMAC}_{\mathrm{i}}\right) \quad(\mathrm{i}=1 \text { to } \mathrm{n})
$$

Where $\mathrm{T}$ is the toxicity risk index for adverse effect, "a", resulting from a time of exposure " $\mathrm{e}$ ", $\mathrm{C}_{\mathrm{i}}$ is the average concentration of the $\mathrm{i}^{\text {th }}$ compound that poses a risk of causing the specific toxic effect in question, and $\mathrm{SMAC}_{\mathrm{i}}$ is the applicable SMAC for the $\mathrm{i}^{\text {th }}$ compound and time of exposure " $\mathrm{e}$ ". There are " $\mathrm{n}$ " ratios for " $\mathrm{n}$ " compounds in the category causing the specific adverse effect. This can be applied to our example of four freons in a simple way because the risk of an adverse effect does not increase with time of exposure. Our Eq. (ignoring units) then becomes:

$$
\text { cardio }^{T}={ }_{\text {cardio }} \sum\left(\mathrm{C}_{\mathrm{i}} / \mathrm{SMAC}_{\mathrm{i}}\right)=35 / 140+20 / 50+108 / 540+30 / 50=1.45
$$

Since we found cardio $^{T}$ to be greater than 1 , and if we trust our conservative assumptions, then the risk of a cardiotoxic effect, specifically a heart arrhythmia, has exceeded an acceptable risk even though no individual Freon has come close to exceeding its SMAC. If such a condition were to be found in a spacecraft atmosphere, then the crew would be prudent to quickly determine how to get the Freons under better control. Furthermore, this would certainly not be the time to exercise or venture out on a stressful ExtraVehicular Activity (EVA).

We have identified 16 distinct toxic effects that could be induced by air pollutants found in the atmosphere of the ISS. In Table 2 we have selected six of the sixteen possible effects and applied these to the pollutants listed in Table 1. Note that many pollutants can be expected to induce two distinct effects, and some not shown here can induce three or more adverse effects. For example, isoprene can induce anemia in addition to the two effects indicated in Table 2 , respiratory system injury and central nervous system depression. ${ }^{8}$

\section{Table 2. Potentially toxic effects that could be induced by the compounds listed.}

\begin{tabular}{|l|l|l|l|l|l|l|l|}
\hline Compound & $\begin{array}{l}\text { Respiratory } \\
\text { System } \\
\text { Injury }\end{array}$ & $\begin{array}{l}\text { Hepatotoxic } \\
\text { (liver) }\end{array}$ & $\begin{array}{l}\text { Mucosal } \\
\text { Irritant } \\
\text { (eyes and } \\
\text { upper } \\
\text { airways) }\end{array}$ & $\begin{array}{l}\text { Central } \\
\text { Nervous } \\
\text { System } \\
\text { Depression }\end{array}$ & $\begin{array}{l}\text { Ototoxic } \\
\text { (Auditory) }\end{array}$ & $\begin{array}{l}\text { Visual } \\
\text { Disturbances }\end{array}$ & Headache \\
\hline Methanol & & & & & & $\mathrm{X}$ & \\
\hline Ethanol & & $\mathrm{X}$ & $\mathrm{X}$ & & & & \\
\hline Acetaldehyde & & & $\mathrm{X}$ & & & & \\
\hline Propenal & & & $\mathrm{X}$ & & & & \\
\hline Acetone & & & & $\mathrm{X}$ & & & $\mathrm{X}$ \\
\hline 2-propanol & & & $\mathrm{X}$ & $\mathrm{X}$ & & & \\
\hline Pentane & & & & & $\mathrm{X}$ & & \\
\hline Dichloromethane & & $\mathrm{X}$ & & & & & \\
\hline Butanal & $\mathrm{X}$ & & & & & & \\
\hline 1-butanol & & & $\mathrm{X}$ & & & & \\
\hline 2-methylhexane & & & & & $\mathrm{X}$ & & \\
\hline 2,3-dimethylpentane & & & & & $\mathrm{X}$ & & \\
\hline Pentanal & $\mathrm{X}$ & $\mathrm{X}$ & & & & & \\
\hline 3-Methylhexane & & & & & $\mathrm{X}$ & & \\
\hline 1-heptane & & & & & $\mathrm{X}$ & & \\
\hline Heptanal & $\mathrm{X}$ & $\mathrm{X}$ & & & & & \\
\hline Isoprene & $\mathrm{X}$ & & & $\mathrm{X}$ & & & \\
\hline Carbon monoxide & & & & $\mathrm{X}$ & & & \\
\hline Formaldehyde & & & $\mathrm{X}$ & & & & \\
\hline Trimethylsilanol & & & & $\mathrm{X}$ & & & \\
\hline Carbon Dioxide & & & & & & & \\
\hline
\end{tabular}

Inspection of the adverse effects will illustrate how the crew's health could be affected in different ways. Mucosal irritants, central-nervous-system depressants, auditory toxicants, and those causing headaches and visual disturbances could possibly be sensed by the crew during their exposure. Mucosal irritants might be sensed as nasal 
itching, watery eyes or a raspy throat. Central-nervous-system depressants would act much like alcohol to slow reaction times and impair judgment. Auditory toxicants would interfere with the crew's ability to hear. It should be noted that in setting SMACs we have considered the interactive effects of a noisy environment and airborne ototoxicants. Obviously, the crew could tell whether they have a headache; however, headaches of unknown origin are not uncommon during spaceflight. The known or suspected causes of these can include head-ward fluid shifts (increased pressure), stress aboard the vehicle, high carbon dioxide levels, and strong odors. Visual disturbances tend to be subtle and are not likely to be detected unless the crew is being tested for responses that depend on visual acuity, depth perception, and tracking ability.

The effects that would not be apparent to the crew during spaceflight, but would be of interest to flight surgeons after the flight are the following: respiratory system injury, hepatotoxicants, and ototoxicants. Respiratory system injury could be evident on spirometery testing or perhaps by lung imaging techniques. The effect of hepatotoxicants could be detected most readily by liver enzyme panels measured in serum. Lasting effects of ototoxicity, of course, could be detected through audiograms. If a crewmember were exposed to excessive airborne toxicants that induce such effects, then the physicians performing longitudinal studies would be alert to the possibility that these bodily systems could be impaired. Of course, there are many other life factors that can lead to disease of the respiratory, hepatic, and auditory systems.

\section{Crew Health Risks from Exposure to Air Pollutants}

The hypothetical, time-weighted concentrations compiled over a 6-month period (Table 1) can be combined with the target toxic effects of each of the compounds to determine the level of risk associated with each toxic effect as shown in Table 3. A group T-value less than 1.0 suggests that the aggregate of air pollutants has an acceptable risk of inducing the specific toxic effect associated with the group. Only the irritant group has a T value greater than 1.0. Reports of mucosal irritation from ISS crews are rare even though ${ }_{\text {irritant }} \mathrm{T}$ often exceeds 1.0. This may be due to the ability of humans to adapt to low levels of mildly irritating compounds in the air. The only specific compound

Table 3. Potentially toxic effects from 6-month exposures to typical compounds found in ISS air

\begin{tabular}{|l|l|l|l|l|l|l|l|}
\hline Compound & $\begin{array}{l}\text { Respiratory } \\
\text { System } \\
\text { Injury }\end{array}$ & $\begin{array}{l}\text { Hepatotoxic } \\
\text { (liver) }\end{array}$ & $\begin{array}{l}\text { Mucosal } \\
\text { Irritant } \\
\text { (eyes and } \\
\text { upper } \\
\text { airways) }\end{array}$ & $\begin{array}{l}\text { Central } \\
\text { Nervous } \\
\text { System } \\
\text { Depression }\end{array}$ & $\begin{array}{l}\text { Ototoxic } \\
\text { (Auditory) }\end{array}$ & $\begin{array}{l}\text { Visual } \\
\text { Disturbances }\end{array}$ & Headache \\
\hline Methanol & & & & & & 0.005 & \\
\hline Ethanol & & 0.000 & 0.000 & & & & \\
\hline Acetaldehyde & & & 0.250 & & & & \\
\hline Propenal & & & 1.000 & & & & \\
\hline Acetone & & & & 0.150 & & & 0.150 \\
\hline 2-propanol & & & 0.007 & 0.007 & & & \\
\hline Pentane & & & & & 0.017 & & \\
\hline Dichloromethane & & 0.020 & & & & & \\
\hline Butanal & 0.015 & & & & & & \\
\hline 1-butanol & & & 0.010 & & & & \\
\hline 2-methylhexane & & & & & 0.008 & & \\
\hline 2,3-dimethylpentane & & & & & 0.008 & & \\
\hline Pentanal & 0.006 & 0.006 & & & & & \\
\hline 3-Methylhexane & & & & & 0.008 & & \\
\hline 1-heptane & & & & & 0.008 & & \\
\hline Heptanal & 0.050 & 0.050 & & & & & \\
\hline Isoprene & 0.100 & & & 0.100 & & & \\
\hline Carbon monoxide & & & & 0.235 & & & \\
\hline Formaldehyde & & & 0.333 & & & & \\
\hline Trimethylsilanol & & & & 0.375 & & & \\
\hline Carbon Dioxide & & & & & & & \\
\hline T Value by Group & 0.171 & 0.076 & 1.600 & 0.867 & 0.049 & 0.005 & \\
\hline
\end{tabular}


known to cause mucoal irritation during spaceflight is $\mathrm{LiOH}$ dust, which can be released from carbon dioxide absorption canisters immediately after they are replaced in the space shuttle.

\section{Communicating Toxicological Information to the Crew}

The crew should be able to interpret air quality data in terms that they can readily understand, and then determine if they are being affected by air pollutants. Figure 2 shows how future displays could readily communicate air quality data in a relevant form to the crew. Inspection of a display much like that in Figure 2 will immediately tell the crew if they should be on the lookout for symptoms. This plot was constructed from data in Table 3.

This can also work in the other direction. For example, if the crew were experiencing an unusual incidence of headaches, then the air quality monitoring system could be quieried to determine if the cause could be an increase in the concentration of compounds associated with headaches.

The air quality monitoring system should store data so that crews can quiery the database for any increased risks associated with a specific period of time. Once a real-time monitor with broad-spectrum capability becomes operational aboard ISS, the crew may want to determine over a specific period of time if pollutants in a toxicological category have increased to risky levels. For example, a newly-arrived module may have been opened six hours ago and the crew has felt malaise, headache, and eye irritation for the past few hours. The crew could ask for a plot of data by toxicological group over the past ten hours. These data

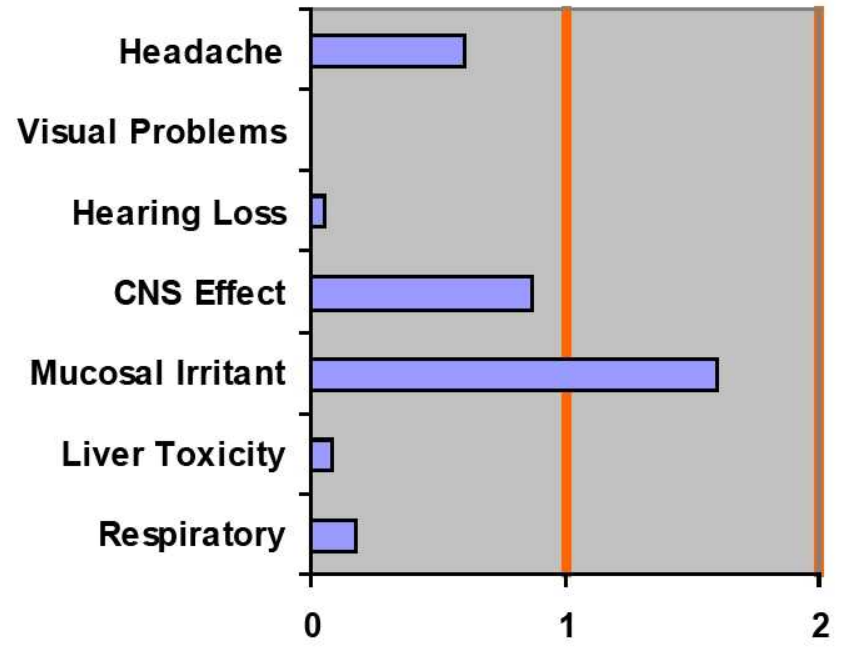

Figure 2. Hypothetical display of air quality data. Bars less than 1 in length suggest that there is no risk of the toxic effect from airborne pollutants. Bars that exceed 1 in length suggest that the crew should be looking out for symptoms associated with that effect. CNS $=$ central nervous system.

can then be compared to a "nominal" data set to determine if there was an increase in central nervous system depressants, headache-causing compounds, or irritants originating from the new module. The "nominal" data set could be something as simple as the baseline average concentrations of each compound or a data set obtained during nominal operations before the module was opened.

While there is certainly value in this approach, it must be viewed as merely a starting point. For example, a recently arrived module to the ISS was entered on September 18, 2009. The crew was immediately aware of a new strong, but somewhat pleasant smell-like that of a new car interior. However, over the next few days as they worked to remove materials from the module, two of the crewmembers began to experience mild headaches. A crewmember had taken a sample of air from the module at first entry, but later ground-based analyses of that sample using gas chromatography/mass spectrometry did not reveal any compounds from the module air that could be specifically associated with causing headaches. The human olfactory system is extremely sensitive and strong odors are well known to induce mild headaches in susceptible people. The compounds causing the odor were apparently below the detection limit of the analytical instruments or outside the analytical window.

\section{Conclusions}

NASA is on the threshold of being able to provide rapid, real-time analysis of trace air pollutants in spacecraft. Raw analytical data will be difficult for the crew to interpret in terms they can use to protect their health and trouble-shoot problems. The SMACs developed by NASA in cooperation with the NRCCOT provide the means of grouping compounds according to their toxic effects so that the health risk associated with the combined group of pollutants on a specific target organ or bodily system can be estimated. Our goal is to make air quality data as useful to crewmembers as possible. Furthermore, after the flight the scientists investigating the longitudinal health status of crewmembers will be able to deduce if exposures to air pollutants may have caused long-term, delayed health effects that they should be attempting to detect. 


\section{References}

${ }^{1}$ Limero, T. F., P. Cheng, E. Reese, and J. Trowbridge. Results of the air quality monitor's experiment to measure volatile organic compounds aboard the International Space Station. $40^{\text {th }}$ International Conference on Environmental Systems, AIAA, Barcelona, Spain, July 12-15, 2010

${ }^{2}$ National Research Council, Spacecraft Maximum Allowable Concentrations for Selected Airborne Contaminants, V 5 , National Academy Press, Washington, DC, 2008

${ }^{3}$ Lutz, WK, S Vamakas, A Kopp-Schneider, J Schlatter, and H Stopper. Deviation from additivity in mixture toxicity; Relevance of nonlinear dose-response relationships and cell line differences in genotoxicity assays with combinations of chemical mutagens and gamms radiation. Environ Health Perspect 110, Suppl 6, 915-918, 2002

${ }^{4}$ Garcia, H. D. Trichlorofluoromethane (Freon 11) Spacecraft Maximum Allowable Concentrations for Selected Airborne Contaminants, V 4, National Academy Press, Washington, DC, 2000, pp. 211-226

${ }^{5}$ Garcia, H. D. Freon 113 Spacecraft Maximum Allowable Concentrations for Selected Airborne Contaminants, V 1, National Academy Press, Washington, DC, 1994, pp. 121-138

${ }^{6}$ Garcia, H. D. Dichlorodifluoromethane 9Freon 12) Spacecraft Maximum Allowable Concentrations for Selected Airborne Contaminants, V 4, National Academy Press, Washington, DC, 2000, pp. 227-239

7 Garcia, H. D. Dichlorofluoromethane Spacecraft Maximum Allowable Concentrations for Selected Airborne Contaminants, V 4, National Academy Press, Washington, DC, 2000, pp. 175-189

8 James, J. T. Spacecraft Maximum Allowable Concentrations for Selected Airborne Contaminants, V 5, National Academy Press, Washington, DC, 2000, pp. 89-118 